\title{
Classification of BINUS University Student Organizations' Logos from the Perspective of Visual Construction
}

\author{
Candi Reggi Sonia ${ }^{1}$, Petrus Lakonawa ${ }^{2}$ \\ ${ }^{1}$ New Media Program, Visual Communication Design Department, School of Design, \\ Bina Nusantara University, Jakarta 11480, Indonesia \\ csonia@binus.edu \\ ${ }^{2}$ Character Building Development Center, Computer Science Department, \\ Bina Nusantara University, Jakarta 11480, Indonesia \\ plakonawa@binus.edu
}

Received: November 2th, 2018/ Accepted: March 6th, 2019

\begin{abstract}
This research focuses on the classification of BINUS University student organizations' logo using textual qualitative approach. It aims at analyzing how they chose the shape of the logo in order to express their identity. This research is framed by three significant focal points in view of its construction namely, the combination of picture mark and letter mark, the integration of picture mark within letter mark or vice versa, and letter mark only. The result of this research shows that the officials of the organizations tend to choose logo that has aesthetic quality in simple visual form rather than complicated one. This research also closely observes the making process of the logo and its classification up to its final appointment as the official logo of the student organizations.
\end{abstract}

\section{INTRODUCTION}

The word Logo, which is etymologically derived from Greek term, has undergone several significant transformations of meaning throughout the history from its original meaning, word, reason, speech, language, et cetera to mean symbol, image, semiotics, et cetera. Nowadays, logo is associated with emblem, flag, signature, sign, symbol or brand which is not saleable directly, yet it gives rise to an identity, information, persuasion which at the end can function as a marketing tool. [1]

Logo as we know now is an abbreviation of logotype which is a written name of an entity that is specifically designed with lettering technics popularized in 1810-1840, while the term logo itself become known in 1937. Logo is usually formed by writings, image, picture, visual illustration, and so on. Logogram is a symbolic writing which represents word or meaning just like the symbol '+' represent the word addition or plus, or '2' represents the word 'two'. It functions as identity marker. It is distinctive so as to differentiate it from others as well as to characterize and avoid any plagiarism, and to signify a quality assurance. [2]

In its later development, logo has gone beyond convention. It has flexible classification. In terms of construction, it has 3 categories: firstly, a combination of picture mark and letter mark (in which the element of picture is separated from the letters); secondly, letter mark in a form of a picture (it can be called as picture, but also letters or as a combination of the two); and thirdly, letter mark only (it is composed of letters only). [2]

Generally, logo is formed by basic shapes or primitive shapes such as rectangular, circular or triangular shapes. When combined, they will form more complicated objects with picture and letter. Each logo creates interpretation of meaning or message. The meaning or message is connected with the appearance of the logo. Therefore, it is very significant to construct a logo according to the message it wishes to communicate. [3] 


\section{PROBLEM STATEMENT}

In the beginning of 2016, BINUS student organizations felt the need to redesign their logos so as to stay updated with their contemporary situation after more than a decade of using their old logos.

\section{THE METHOD}

This research is done in qualitative method while all the data is observed and interpreted from its appearance. Every logo is always built up by basic shapes/primitive shapes' becomes the foundation of this research aside from the theory of Per Mollerup (1983) about the Taxonomy of Trademarks (picture mark and letter mark). [2] At the end, this research will argue further with the theory of basic approach in visual communication theory that visual communication process should be understood broadly through theories, principles and techniques that may help to solve visual problems, namely, communication theories, semiotic theories, theories of perception and shape's aesthetics. [1]

\section{RESULTS AND DISCUSSIONS}

BINUS student organizations felt the need to redesign their logos so as to stay updated with their contemporary situation after more than a decade of using their old logos. They follow several phases of logo making process. It starts from researching of the history of each organization, analyzing its core nature, vision and mission then discussing with the advisers, seniors and alumni of the organization regarding the essentials that logos should contain and express. [4]

After that, the sketches are made into thumbnails while the decision makers decide on visual representation of organizations values and characters. With the use of computer software, the logos were finalized. The logos then were presented in formal meetings of the organizations to be reviewed and voted on, then the formal selected logos were presented to the official management of the BINUS University for Approval by Prof. Dr. Ir. Harjanto Prabowo, MM. (Rector of BINUS University). Analyzing the logos of BINUS student organizations using the theory of basic/primitive shapes and the theory of trademark's taxonomy (Per Mollerup, 1983) this research comes up with a classification of the logos as it is shown below.

The classification by shapes and taxonomy of picture mark and letter mark shows that the logos took some basic/primitive shapes namely rectangular, circular and triangle shapes. They range from abstract to concrete forms. The concrete forms took three main taxonomies, namely picture mark, letter mark, and the combination between picture mark and letter mark. [2]

From the perspective of the relation between sign and the values it signifies, it is obviously identifiable that there are basic structural shapes which are shown through its visual images. Yet, not all logos apply ideal visual elements (dot, line, and color, size, proportion, and texture) while aesthetic quality of a logo depends gravely on harmonious unity which is characterized by the balance, contrast, harmony, accent, emphasis, proportion, simplicity, repetition, dominance, rhythm, and movement. [1] 


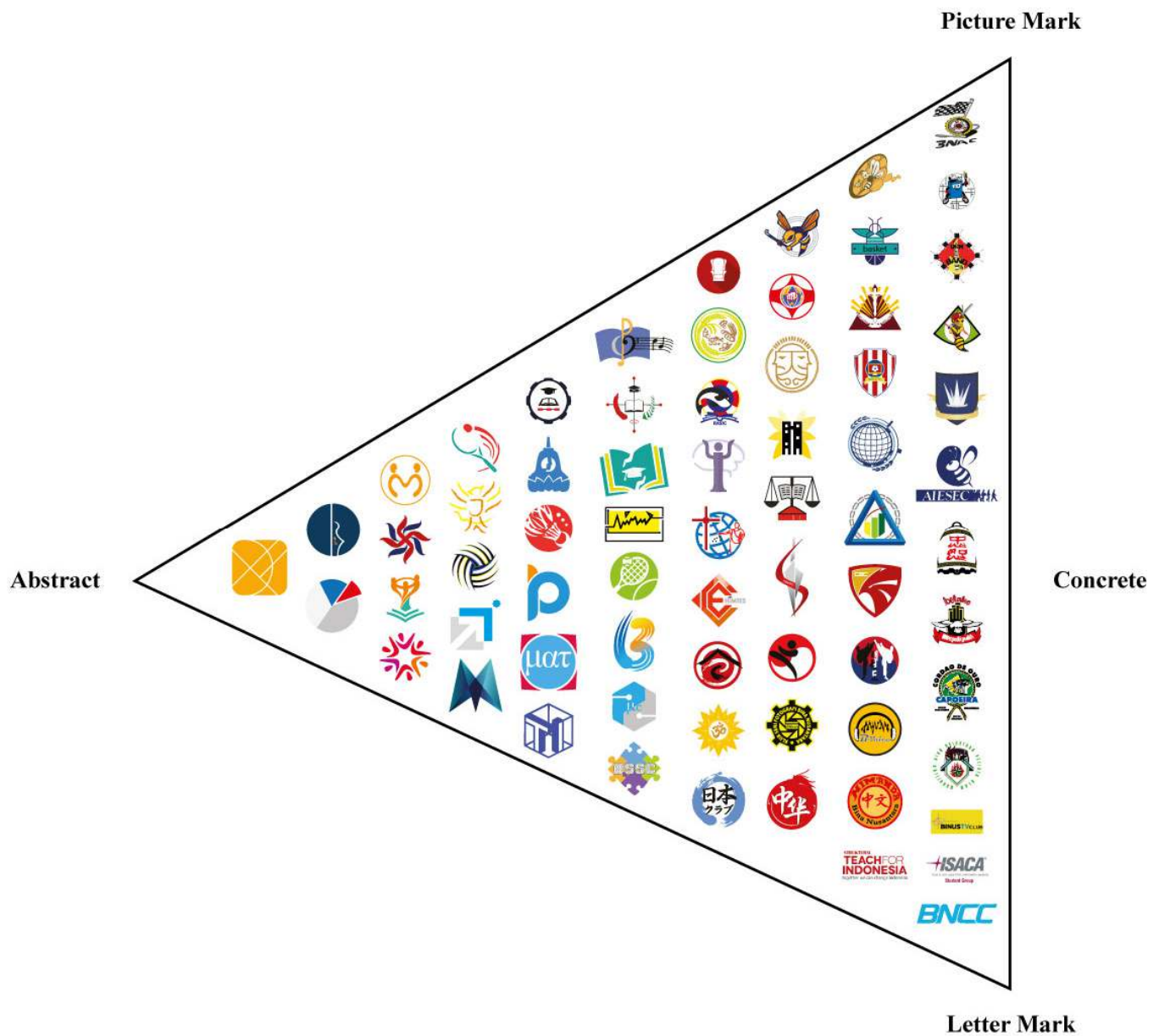

Figure 1 Classification Student Organization Logo at BINUS University

At least all logos share something in common. They maintain simplicity, balance, and harmony as their basic character. The circular shape expresses flexibility and dynamism as circle visually symbolizes continuous movement and improvement. Majority chose professionalism and maturity as their identity by using blue and white as their dominant colors, while others emphasize on familial bonding as they use yellow and orange as their background color. [5]

Some logos (from the middle area above) take semi abstract forms with picture mark style. These logo give impression of putting dense visual illustration. From the perspective of these logos represent express meaning of what they try to symbolize. The constraint of these kind of logo is that they lose their uniqueness and their sense of flexibility. These kind of logos cannot last long in the face of consistent change in time. Meaning changes in time as the interpretation of visual elements change. Logo will change according to what it wish to mean. Semi abstract and letter mark logos generally remain long, hardly change because they use simple visual patterns such as circular shape, dominant color with proportional size and typography, as well as clear font type and its sufficient level of readability. 


\section{CONCLUSION}

In the making of logo, it is necessary to profoundly analyze the background of its organization especially the nature, the character, the vision and the mission of the organization. Those matters should be visualized through the logo. The logo should be able to communicate the core identity of the organization to the public. The identity of the organization defines its classification in terms of its shapes and taxonomy.

Furthermore, aesthetic quality of a logo should be taken into account. Logo should be able to combine the aspects of balance, harmony, simplicity and uniqueness. Logo is a symbolic image of the organization. It is the brand, a trademark of the organization. It should capture what it symbolizes, from denotative to connotative transferring of the meaning/message.

\section{REFERENCES}

[1] Safanayong, Y 2006 Desain Komunikasi Visual Terpadu. Jakarta: Arte Intermedia

[2] Rustan, S 2009 Mendesain Logo Jakarta: PT Gramedia Pustaka Utama

[3] Morissan 2013 Teori Komunikasi, Individu hingga Massa Jakarta: Kharisma Putra Utama

[4] Stephen, W. L 2011 Teori Komunikasi Jakarta: Salemba Humanika

[5] Nugraha, N. (Ed.) 2018, 23 Jan Teokom Teori Simbol. Retrieved January 23th 2018 from http://www.academia.edu/11623084/Teokom-teori-simbol 